\title{
Real-life Diagnostic and Therapeutic Approach to CLL: A New Proposal from an Expert Panel in Tuscany Region
}

\author{
Monica Bocchia ${ }^{1}$, Alberto Bosi $^{2}$, Enrico Capochiani ${ }^{3}$, Stefania Ciolli ${ }^{4}$, Romano \\ Danesi ${ }^{5}$, Sara Galimberti ${ }^{6}$, Alessandro Gozzetti ${ }^{7}$, Sabrina Moretti ${ }^{8}$, Ubaldo Occhini ${ }^{9}$, \\ Mario Petrini ${ }^{10}$ \\ AOU Senese, UOC Hematology, Siena \\ AOU Careggi, Unità Funzionale di Ematologia, Firenze \\ 3 Azienda Usl Toscana nord ovest, Ospedale di Livorno USL6, UO Dipartimentale di Ematologia, Livorno \\ 4 SODc di Ematologia - Azienda Ospedaliera Universitaria Firenze \\ AOU Pisana, UO Farmacologia Clinica e Farmacogenetica, Pisa \\ 6 Department of Clinical and Experimental Medicine, UO Hematology, University of Pisa \\ Hematology, University of Siena, Policlinico Le Scotte \\ SoS Ematologia clinica e Oncoematologia, Firenze SOC Oncoematologia Dipartimento Oncologico, ASL toscana Centro \\ Azienda Usl Toscana sud est, Ospedale San Donato - UO Ematologia, Arezzo \\ 10 AOU Pisana, UO Ematologia, Pisa
}

\section{ABSTRACT}

BACKGROUND: In the last years genomic and somatic alterations have shown to play a pivotal role in the pathogenesis of chronic lymphocytic leukemia (CLL) and new prognostic factors have been identified accordingly.

AIM: To describe a real-life diagnostic and therapeutic approach to CLL that takes into account the role of genomic and somatic prognostic factors in the risk stratification of developing progressive disease, and treatment decision.

METHODS: This new proposal has been developed and validated by ten key opinion leaders from Tuscany Region during two Expert Meetings. The approach suggested comes from their experience in daily clinical practice and is supported by guidelines recommendations, clinical trials results, and drugs prescribing conditions in Italy.

RESULTS: Beside TP53 deletion or mutated status, the Expert Panel highlighted the importance of the IGHV mutation status characterization, since the diagnosis, in order to identify patients who will have a more aggressive progression. Furthermore, just before starting treatment, to obtain useful prognostic information and indication in the selection of the therapy, they recommend cytogenetic analysis for the detection of del(11q), trisomy 12, del(13q), del(17p), conventional karyotyping of stimulated CLL cells, TP53 sequencing, and molecular genetic analysis to detect IGHV mutation status. CONCLUSIONS: The Expert Panel recognized the limitations associated with traditional staging systems in identifying patients who will have a more aggressive disease course and predicting response to treatment and suggested a real-life diagnostic and therapeutic approach to CLL to update the current patient management in light of recent advances that have improved understanding of CLL.
\end{abstract}

\section{Keywords}

Chronic lymphocytic leukemia; Prognostic factors; TP53 deletion; IGHV mutation status

\section{BACKGROUND}

Chronic lymphocytic leukemia (CLL) is a chronic lymphoproliferative disorder characterized by progressive accumulation of monomorphic B-cells in peripheral blood, bone marrow, spleen, and lymph nodes.

CLL represents the most common form of leukemia of adults in Western countries [1]. The Surveillance, Epidemiology, and End Results (SEER) program of the National Cancer Institute (NCI) reports an incidence of 4.9 new cases per 100,000 men and women per year [2]. $\mathrm{CCL}$ is most frequently diagnosed among people aged 65-74 with a median age at diagnosis of 70 years (about two third $\geq 65$ years) and this malignancy is more common among men

Corresponding author Stefania Ciolli

ciolli.stefania@gmail.com

Received: 27 November 2019 Accepted: 10 December 2019 Published: 10 February 2020 


\begin{tabular}{|c|c|}
\hline Stage & Description \\
\hline \multicolumn{2}{|l|}{ Rai $[4,5]$} \\
\hline 0 (low risk risk) & $\begin{array}{l}\text { Lymphocytosis in the peripheral blood and/or in the bone } \\
\text { marrow. }\end{array}$ \\
\hline $\begin{array}{l}\text { I-II (intermediate } \\
\text { risk) }\end{array}$ & $\begin{array}{l}\text { Lymphocytosis in the peripheral blood + enlarged lymph } \\
\text { nodes in any sites }+ \text { splenomegaly and/or hepatomegaly. }\end{array}$ \\
\hline III-IV (high risk) & $\begin{array}{l}\text { Lymphocytosis with disease-related anemia }(\mathrm{Hb}<11 \mathrm{~g} / \\
\left.\mathrm{dL} \text { ) or thrombocytopenia (platelets count }<100 \times 10^{9} / \mathrm{L}\right) \text {. }\end{array}$ \\
\hline \multicolumn{2}{|l|}{ Binet [6] } \\
\hline A & $\begin{array}{l}\mathrm{Hb} \geq 10 \mathrm{~g} / \mathrm{dL}+\text { platelet count } \geq 100 \times 10^{9} / \mathrm{L}+<3 \text { lymph } \\
\text { node areas involved'. }\end{array}$ \\
\hline B & $\begin{array}{l}\mathrm{Hb} \geq 10 \mathrm{~g} / \mathrm{dL}+\text { platelet count } \geq 100 \times 10^{9} / \mathrm{L}+\geq 3 \text { lymph } \\
\text { node areas involved } 1 .\end{array}$ \\
\hline C & $\mathrm{Hb}<10 \mathrm{~g} / \mathrm{dL}$ and/or platelet count $<100 \times 10^{9} / \mathrm{L}$. \\
\hline
\end{tabular}

Table I. Staging systems [4-6]

${ }^{1}$ Presence of enlarged lymph nodes $\geq 1 \mathrm{~cm}$ in diameter or organomegaly. Areas of involvement considered are head and neck (including the Waldeyer ring), axillae, groin, liver, and spleen

\begin{tabular}{lc}
\hline \multicolumn{1}{c}{ Prognostic factors } & 10-year OS \\
\hline Del(17p) vs non del(17p) & $-87 \%$ \\
Serum $\beta_{2}$-microglobulin concentration $>3.5 \mathrm{mg} / \mathrm{L}$ vs $\leq 3.5 \mathrm{mg} / \mathrm{L}$ & $-73 \%$ \\
Unmutated vs mutated IGHV & $-68 \%$ \\
Mutated vs unmutated TP53 & $-55 \%$ \\
Binet stage B vs A & $-56.8 \%$ \\
Binet stage C vs A & $-46.4 \%$ \\
Age $>65$ vs $\leq 65$ years & $-39 \%$ \\
\hline
\end{tabular}

Table II. Impact of the independent factors identified by the CLL-IPI. Elaboration from [12]

\begin{tabular}{llc}
\hline Risk group & \multicolumn{1}{c}{ Prognostic factors } & 10-year OS \\
\hline Low & Mutated IGHV and no del(17p)/del(11p) & $82 \%$ \\
Intermediate & Unmutated IGHV or del(17p)/del(11p) & $52 \%$ \\
High & Unmutated IGHV and del(17p)/del(11p) & $27 \%$ \\
\hline
\end{tabular}

Table III. Risk groups identified by the Barcelona score [13] than women ( 6.8 vs 3.5 per 100,000 persons, respectively) [2].

The clinical course of the disease is extremely variable: while the majority of CLL patients is asymptomatic at diagnosis and becomes symptomatic within a few years, a part of patients remains asymptomatic for decades with a percentage of $20-30 \%$ who presents a life expectancy equal to that of the general population [3]. Due to this heterogeneity, it is very important to identify, since the diagnosis, which patients will have a more aggressive progression.

The oldest, and still most used, staging systems in CLL are Rai [4,5] and Binet [6] classifications. Both of them define three prognostic groups with different disease burden (Table I) and are only based on physical examination (lymph node involvement, hepatomegaly, and/or splenomegaly) and blood test results (presence of anemia or thrombocytopenia).

Despite their widespread use, these classifications have shown some limitations in identifying patients who will have a more aggressive disease course and predicting response to treatment [7].

Recently, genomic and somatic alterations have shown to play a pivotal role in the pathogenesis of CLL and new prognostic factors have been identified accordingly.

In particular, studies on the variable region of the immunoglobulin heavy chain gene (IGHV) have shown that the unmutated gene is associated with a worse prognosis and a significant reduction of survival compared to patients with mutated pattern $[8,9]$. Also, the advances on cytogenetic alterations allowed to identify patients with favorable [del(13q)] and unfavorable $[\operatorname{del}(11 \mathrm{q})$, del(17p)] prognosis $[10,11]$. The presence of $\operatorname{del}(17 \mathrm{p})$, which reflects the loss of TP53 gene, is frequently associated with the mutation of the remaining TP53 allele and worse outcomes and shorter survival [10,11]. Furthermore, the mutation of TP53 is associated with a reduction of overall and progression free survival (PFS), even in the absence of del(17p) [10,11].

From these findings, new prognostic scores have been developed in order to overcome the limitations of the classical staging systems.

The international prognostic index for patients with chronic lymphocytic leukemia (CLLIPI) [12] used data from 3472 patients and identified five independent prognostic factors impacting 5-year overall survival (OS): deleted or mutated TP53 status, unmutated IGHV, serum $\beta_{2}$-microglobulin $>3.5 \mathrm{mg} / \mathrm{L}$, Binet stage B/C or Rai I-IV, and age $>65$ years. Furthermore, the results of the univariate analyses showed the impact of each factor on CLL 10-year prognosis (Table II).

The Barcelona score [13] aimed at simplifying the CLL-IPI developing a biomarkers-only prognostic system based on the two most important prognostic factors: IGHV mutational status and fluorescence in situ hybridization (FISH) cytogenetics. Barcelona score identify three risk groups with different 10-year OS (Table III).

These novel prognostic factors aim at assisting patient management (i.e., define the follow-up strategy based on the risk of developing progressive disease, especially for patients with low tumor burden at diagnosis) and treatment decision [7]. The presence of del(17p) and/ or mutated TP53 has in fact been associated with resistance to standard chemotherapy regi- 
mens (i.e., alkylating drugs and/or purine analogs) and poor response to chemoimmunotherapy [10], while better outcomes have been achieved with novel inhibitors [10]. Similarly, the presence of mutated IGHV genes identify patients who have long-term disease free-survival after the treatment with fludarabine, cyclophosphamide, and rituximab (FCR) [14], while in patients with the unmutated IGHV pattern the treatment with the novel BTK inhibitor ibrutinib is associated with better outcomes when compared with chlorambucil (CHL) [15-17].

Recently published international guidelines and expert recommendations [10,11,18-21] have already recognized the usefulness of the new diagnostic and prognostic factors in the management of patients with CLL.

\section{AIM}

Aim of this paper is to describe a real-life diagnostic and therapeutic approach to CLL proposed by an Italian Expert Panel with the objective to update the current patient management in light of recent advances that have improved understanding of CLL. This new proposal has been developed and validated by ten key opinion leaders from Tuscany Region during two Expert Meetings. The approach suggested comes from their experience in daily clinical practice and is supported by guidelines recommendations, clinical trials results, and drugs prescribing conditions in Italy.

\section{DIAGNOSIS OF CLL}

Onset of CLL is usually asymptomatic and the disease is discovered incidentally after a blood count evaluation performed for another reason. To differentiate CLL from MBL (monoclonal B-cell lymphocytosis), the diagnosis of CLL requires the presence, for at least three months, of $\geq 5 \times 10^{9} / \mathrm{L}$ monoclonal B cell lymphocytes in the peripheral blood $[10,11]$. The clonality of B-cells must be confirmed by flow cytometry in order to detect the CLL peculiar immunophenotypic profile: clonal kappa or lambda light chain restriction, co-expression of the surface antigen CD5 and the B-cell antigens CD19, CD20, and CD23, high expression of CD200 [22] and low levels of surface immunoglobulin CD20 and CD79b [10,11].

Table IV reports the examinations recommended to confirm the diagnosis of CLL and predict patient prognosis $[10,11]$.

In particular, molecular analysis to detect IGHV mutation status can provide useful prognostic information, especially in patients with low tumor burden at diagnosis, and enable physicians to provide more accurate patient counseling and define the frequency of follow-up. Furthermore, IGHV mutation status remains unchanged over time; thus it can inform therapy selection before starting treatment $[7,10-13,23,24]$.

\begin{tabular}{|c|c|}
\hline Time & Examinations recommended \\
\hline At diagnosis & $\begin{array}{l}\text { - Detailed anamnesis with particular attention to prior or current malignancy. } \\
\text { - Blood tests: CBC, LDH, creatinine, total protein levels, serum protein electrophoresis, transaminases, bilirubin, } \\
\beta_{2} \text {-microglobulin, IgG, IgA, and IgM levels. } \\
\text { - Microscopic examination of the peripheral blood smear. } \\
\text { - Immunophenotype: flow cytometry on peripheral blood lymphocytes. } \\
\text { - Physical examination (abdomen and palpable lymph nodes). } \\
\text { - Imaging: ultrasound and X-ray of chest. } \\
\text { - Molecular analysis: IGHV mutation status (Sanger or NGS). }\end{array}$ \\
\hline $\begin{array}{l}\text { At follow-up } \\
\text { (asymptomatic } \\
\text { patients) }\end{array}$ & $\begin{array}{l}\text { - Blood tests: CBC, LDH, creatinine, total protein levels, serum protein electrophoresis, transaminases, bilirubin, } \\
\text { b2-microglobulin, IgG, IgA, and IgM levels. } \\
\text { - Physical examination (abdomen and palpable lymph nodes). } \\
\text { - Imaging: abdomen ultrasound at least } 1 \text { time every } 12 \text { months }{ }^{1} \text {. }\end{array}$ \\
\hline $\begin{array}{l}\text { Before } \\
\text { treatment }\end{array}$ & $\begin{array}{l}\text { - Detailed anamnesis with particular attention to polypharmacy e comorbility index (CIRS, ECOG, and Charlson). } \\
\text { - Blood tests: as at diagnosis + QuantiFERON, infectious disease status (HBV, HCV, HIV; if IgG < } 500 \mathrm{mg} / \mathrm{dl} \\
\text { detection/quantification of viral genomes). } \\
\text { - Cytogenetic analysis: FISH on peripheral blood lymphocytes for chromosomes 11, 12, 13, and 17; conventional } \\
\text { karyotyping of stimulated peripheral blood lymphocytes (aCGH). } \\
\text { - Molecular analysis: IGHV mutation status (if not performed at diagnosis), TP53 mutation status (Sanger or NGS, } \\
\text { cut off > 10\%). } \\
\text { - Heart tests: ECG, ECOCG. }\end{array}$ \\
\hline
\end{tabular}

Table IV. Examinations recommended at diagnosis, follow-up, and before treatment

1 Timing to be defined according to clinical need

aCGH = array-based Comparative Genomic Hybridization; CBC = complete blood count; CIRS = Cumulative IIIness Rating Scale; ECG = electrocardiogram; ECOCG = echocardiogram; ECOG = Eastern Cooperative Oncology Group; FISH = Fluorescence in situ hybridization; IGHV = Immunoglobulin Heavy Chain Variable Region; LDL = low-density lipoprotein; NGS = next generation sequencing 


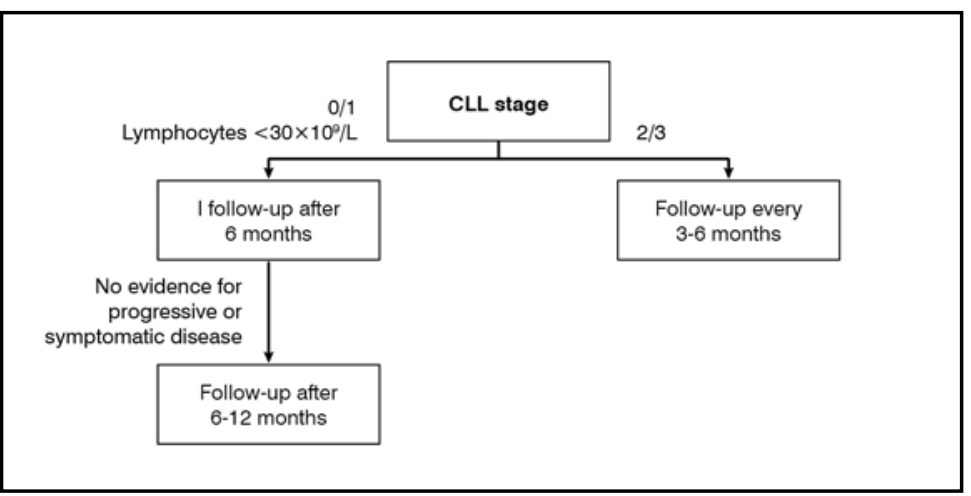

Figure 1. Monitoring of patients without active disease

\section{MONITORING}

According to IwCLL guidelines, patients with asymptomatic early-stage disease should be observed without therapy until disease progression or evidence of diseaserelated symptoms [10].

A "watch and wait" strategy until evidence of active disease is usually recommended also in patients with intermediate and high-risk disease.

As reported in Figure 1, asymptomatic patients with early-stage disease should be followed-up 6 months after diagnosis in order to exclude a rapid disease progression. Afterwards, in case of stable disease, follow-up may take place every 6-12 months. The examinations recommended at each follow-up visit are reported in Table IV.

\section{TREATMENT}

\section{Assessment before treatment}

Table IV reports examinations recommended before treatment. In particular, cytogenetic analysis for the detection of $\operatorname{del}(11 q)$ [10,11,13], trisomy $12[10,11]$, $\operatorname{del}(13 q)[10,11]$, $\operatorname{del}(17 \mathrm{p})[10,11]$, conventional karyotyping of stimulated CLL cells [11,25], TP53 sequencing, and molecular genetic analysis to detect IGHV mutation status can provide useful prognostic information and may guide selection of therapy $[10,11]$.

Since cytogenetic abnormalities can evolve over time, re-evaluation of FISH, stimulated karyotype, and of TP53 mutational status are recommended before each subsequent line of treatment.

Furthermore, the choice of treatment should take into account age, comorbilities, performance status, and creatinine clearance.

\section{Indication for treatment}

As reported above, treatment should only be started in patients with progressive or symptomatic disease (active disease) [10]. Active disease is defined by the presence of at least one of the criteria reported in Table V.

Neither the presence of del(17p), TP53 mutation, or other markers associated with poor prognosis, nor the absolute lymphocyte count, nor lymph node size, without the above mentioned criteria, should be used as indicator for treatment.

\section{Assessment of response to treatment}

In the recent years, the components of the panel acquired a huge experience about the employ of the ultrasound as fundamental tool for the response assessment. Indeed, according to the international guidelines, the quality of response is based on the disappearance/reduc-

\section{Criteria for initiating treatment \\ (at least 1 of the following should be met)}

- Progressive lymphocytosis with an increase of $\geq 50 \%$ over 2 months or LDT $<6$ months (if lymphocytosis $>30 \times 10^{9} / \mathrm{L}$, a longer observation period may be required in patients with lymphocytosis $<30 \times 10^{9} / \mathrm{L}$ )

- Evidence of progressive marrow failure with development (or worsening) of anemia ( $\mathrm{Hb}<10 \mathrm{~g} / \mathrm{dL}$ ) and/or thrombocytopenia (platelet count $<100 \times 10^{\%} / \mathrm{L}$ ).

- Massive ( $\geq 6 \mathrm{~cm}$ from the costal arch) or progressive or symptomatic splenomegaly.

- Massive (nodes with longest diameter $\geq 10 \mathrm{~cm}$ ) or progressive or symptomatic lymphadenopathy.

- Autoimmune anemia and/or thrombocytopenia resistant to corticosteroids.

- Symptomatic of functional extranodal involvement.

- Disease-related systemic symptoms:

- Weight loss $\geq 10 \%$ in the last 6 months

- Significant asthenia/fatigue $(E C O G \geq 2)$

- Fever $\geq 38^{\circ} \mathrm{C}$ for $\geq 15$ days without evidence of infection

- Night sweats for $\geq 1$ months without evidence of infection

Table V. Criteria that define active disease [10] 
tion or stability of the lymph nodes and spleen dimensions, assessed by CT scan and physical examination or by the physical examination only (in the general practice) [10]. In the routine, the physical examination is always subjective, with a high inter-individual variability, and CT scan exposes patient to a biological damage. On the contrary, the ultrasonography is a "biologically safe" technique, with lower variability of interpretation, able to measure with precision the lymph nodes and spleen dimensions and to distinguish the "reactive" from the "still pathological" masses. In conclusion, the experts suggest adding the ultrasound assessment to the physical examination in the clinical daily practice.

\section{I line treatment algorithm}

Figure 2 reports the treatment algorithm proposed by the Expert Panel for the treatment of patients with CLL.

The most important characteristics that guide the choice of therapy are the presence of $\operatorname{del}(17 p)$ and/or mutated TP53, IGHV mutational status, the presence of del(11q), age, and comorbidities.

\section{Patients with TP53 mutation and/or del(17p)}

Since chemoimmunotherapy showed poor outcome, patients with $\operatorname{del}(17 \mathrm{p})$ and/or TP53 mutation should be treated with novel inhibitors.

In particular, in the absence of contraindication, ibrutinib, an inhibitor of Bruton's tyrosine kinase (BTK), is the preferred treatment option [11,26].

Adult patients who are not eligible for chemoimmunotherapy could be considered for therapy with idelalisib (an inhibitor of phosphatidylinositol 3-kinase p110 $\delta$ ), in combination with rituximab [27]; while patients who are unsuitable for B-cell receptor pathway inhibitors, could be considered for therapy with venetoclax (a BCL2 inhibitor) [28].

\section{Patients without TP53 mutation or del(17p)}

In these patients, IGHV mutational status and age are the main drivers to define treatment strategy.

\section{Age $\geq 65$ years}

Unmutated IGHV. In the RESONATE-2 study [15-17], ibrutinib showed significantly higher overall response rate (ORR) and longer PFS compared to CHL and thus it is now the first choice of treatment. For patients who are not eligible to receive ibrutinib (in patients $<70$ years ibrutinib is indicated if at least one of the following criteria are satisfied: creatinine clearance $<70 \mathrm{~mL} / \mathrm{min}$, ECOG 1-2, anemia $<10 \mathrm{~g} / \mathrm{dL}$ or thrombocytopenia $<100.000 / \mu \mathrm{L}$ [29]) the second choice of treatment is the combination of the new anti-CD20 monoclonal antibody obinutuzumab and chlorambucil (G-CHL).

Mutated IGHV. As reported above, ibrutinib is associated with better outcomes compared to CHL [15-17]. Furthermore, the Alliance North American Intergroup Study showed

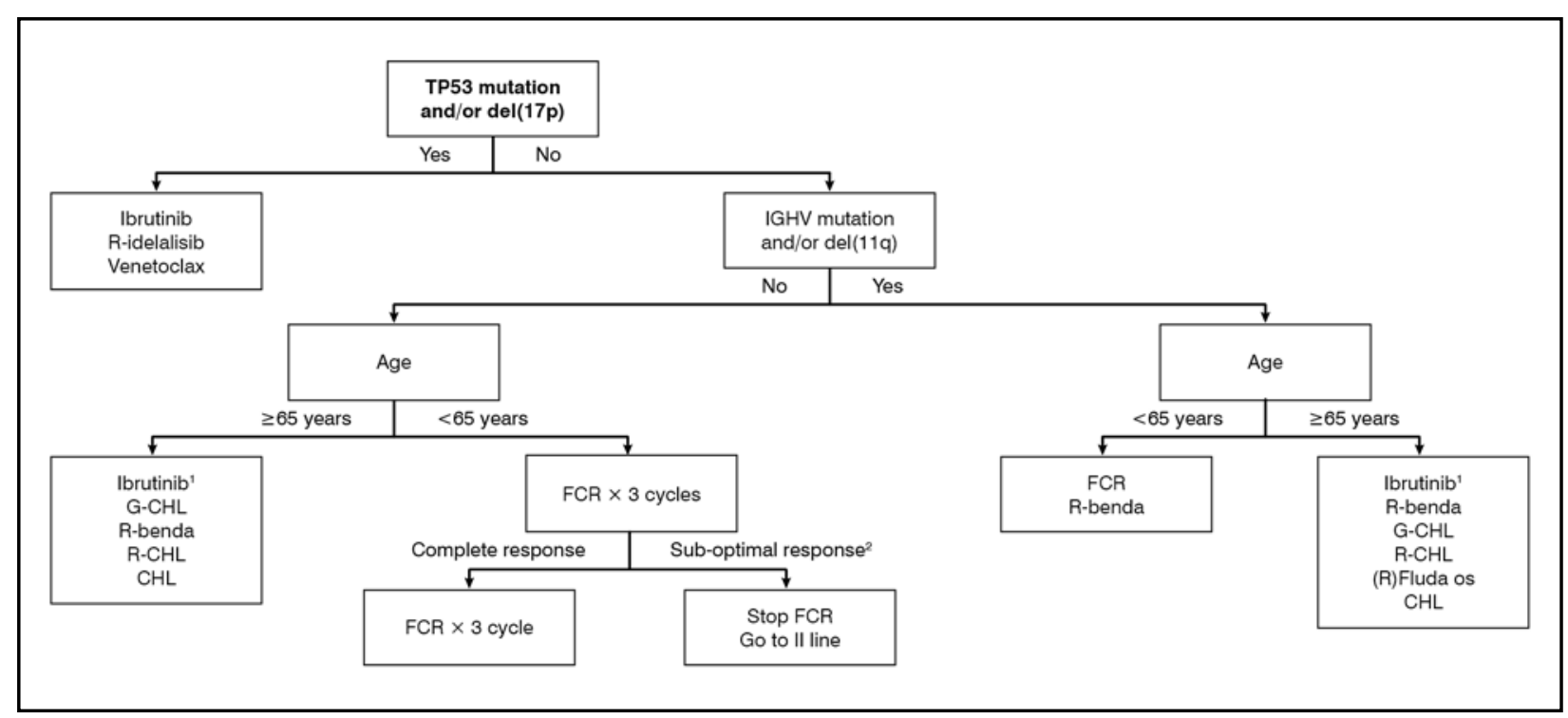

Figure 2. Treatment algorithm for patients with CLL

${ }^{1}$ In patients $<70$ years ibrutinib is indicated if at least one of the following criteria are satisfied: creatinine clearance $<70 \mathrm{~mL} / \mathrm{min}, \mathrm{ECOG} 1-2$, anemia $<10$ $\mathrm{g} / \mathrm{dL}$ or thrombocytopenia $<100.000 / \mu \mathrm{L}[29] ;{ }^{2}$ Evaluated at the discretion of the clinician 


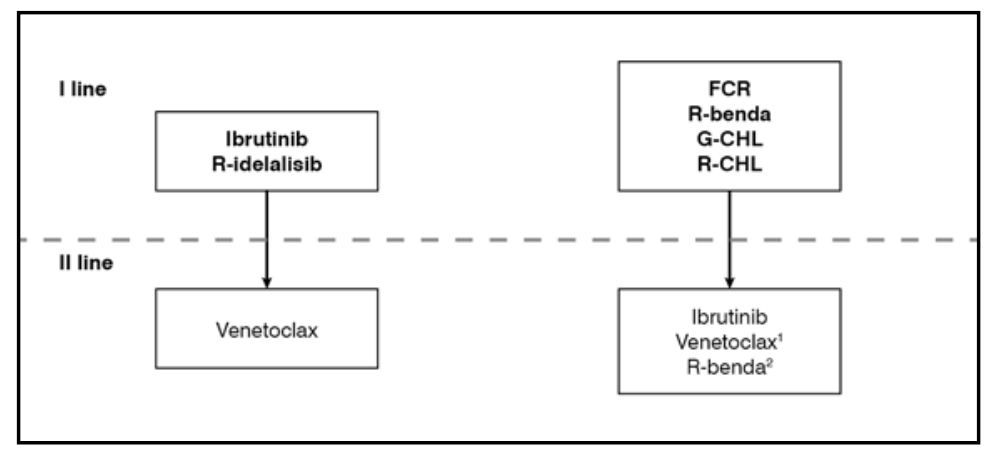

Figure 3. Relapsed therapy

${ }^{1}$ The use of R-venetoclax will be considered after the publication of reimbursement criteria in the Italian Official Gazette

${ }^{2}$ Re-treatment with R-bendamustine should be considered after at least 36 months from relapse only in patients with unmutated TP53 and mutated IGHV status that, among older patients ( $\geq 65$ years), treatment with ibrutinib was superior to the combination of rituximab and bendamustine (Rbendamustine) in terms of PFS [30].

Although OS was not statistically different, chemoimmunotherapy could still be a good option for these patients, when deletion of chromosome 11 has been excluded. The regimens more frequently adopted by the experts resulted: R-bendamustine, low-dose of FCR [31] and G-chlorambucil.

\section{Age $<65$ years}

Unmutated IGHV. Recent studies highlighted the limits of treatment with FCR in young unmutated IGHV patients in favor of

ibrutinib [32]. Waiting for the approval of ibrutinib for this indication, chemoimmunotherapy with FCR remains the standard of care in these patients $[11,14,33]$. Patients who complete 6 cycles of FCR achieve better outcomes [14]; however, based on our clinical experience, we recommend assessing the response already after 3 cycles. In case of complete response (CR), we suggest continuing with FCR regimen for other 3 cycles, otherwise, in case of sub-optimal response (evaluated at the discretion of the clinician), it is recommended to discontinue FCR treatment and move to the II line treatment.

Mutated IGHV. In these patients, the treatments recommended are FCR and R-bendamustine. FCR is associated with better outcomes, while R-bendamustine is associated with less toxic effects [34]; therefore, the choice of type and duration of treatment should be made at the discretion of the clinician.

\section{Relapsed therapy}

According to IwCLL guidelines relapse is defined as «evidence of disease progression in a patient who has previously achieved the above criteria of complete or partial remission for $\geq 6$ months» [10].

Figure 3 reports the recommended relapsed therapies.

\section{CONCLUSIONS}

The Expert Panel, consisting of clinicians with experience in management of CLL, recognized the limitations associated with traditional staging systems in identifying patients who will have a more aggressive disease course and predicting response to treatment.

Therefore, based on their clinical practice, guidelines recommendations, clinical trials results, and drugs prescribing conditions, they suggested a new diagnostic and therapeutic approach that takes into account the role of genomic and somatic prognostic factors in the risk stratification of developing progressive disease, and treatment decision. In particular, beside TP53 deletion or mutated status, they highlighted the importance of the IGHV mutation status characterization, since the diagnosis, in order to identify patients who will have a more aggressive progression. Furthermore, just before starting treatment, to obtain useful prognostic information and indication in the selection of the therapy, they agreed with other groups and guidelines to recommend cytogenetic analysis for the detection of $\operatorname{del}(11 \mathrm{q})$, trisomy 12 , $\operatorname{del}(13 q), \operatorname{del}(17 p)$, conventional karyotyping of stimulated CLL cells, TP53 sequencing, and molecular genetic analysis to detect IGHV mutation status.

\section{Funding}

This work was made possible thanks to an unconditional grant from Janssen Italy.

\section{Conflicts of Interest}

All authors have nothing to disclose regarding this work. 


\section{REFERENCES}

1. Swerdlow SH, Campo E, Harris NL, et al. WHO Classification of Tumours of Haematopoietic and Lymphoid Tissues. In: WHO Classification of Tumours. 4th Edition, Volume 2. IARC: Lyon, 2016

2. SEER Cancer Stat Facts: Chronic Lymphocytic Leukemia. National Cancer Institute. Bethesda, MD. Available at https://seer.cancer.gov/statfacts/html/clyl.html (Last accessed November 2020)

3. Gruber M, Wu CJ. Evolving understanding of the CLL genome. Semin Hematol 2014; 51: 177-87; https://doi.org/10.1053/j.seminhematol.2014.05.004

4. Rai KR, Sawitsky A, Cronkite EP, et al. Clinical staging of chronic lymphocytic leukemia. Blood 1975;46: 219-34; https://doi.org/10.1182/blood.V46.2.219.219

5. Rai KR. A critical analysis of staging in CLL. In: Gale RP, Rai KR, eds. Chronic Lymphocytic Leukemia: Recent Progress and Future Directions. New York, NY: Alan R. Liss; 1987: 253-64

6. Binet JL, Auquier A, Dighiero G, et al. A new prognostic classification of chronic lymphocytic leukemia derived from a multivariate survival analysis. Cancer 1981; 48: 198-206

7. Baliakas P, Mattsson M, Stamatopoulos K, et al. Prognostic indices in chronic lymphocytic leukaemia: where do we stand how do we proceed? J Intern Med 2016; 279: 347-57; https:// doi.org/10.1111/joim. 12455

8. Damle RN, Wasil T, Fais F, et al. Ig V gene mutation status and CD38 expression as novel prognostic indicators in chronic lymphocytic leukemia. Blood 1999; 94: 1840-7; https:// doi.org/10.1182/blood.V94.6.1840

9. Hamblin TJ, Davis Z, Gardiner A, et al. Unmutated $\operatorname{Ig~V(H)~genes~are~associated~with~a~}$ more aggressive form of chronic lymphocytic leukemia. Blood 1999; 94: 1848-54; https:// doi.org/10.1182/blood.V94.6.1848

10. Hallek M, Cheson BD, Catovsky D, et al. iwCLL guidelines for diagnosis, indications for treatment, response assessment, and supportive management of CLL. Blood 2018; 131: 2745-60; https://doi.org/10.1182/blood-2017-09-806398

11. Wierda WG, Byrd JC, Abramson JS, et al. NCCN Clinical Practice Guidelines in Oncology. Chronic Lymphocytic Leukemia/Small Lymphocytic Leukemia. Version 2.2020, October 8, 2019 (Last Accessed October 2019)

12. International CLL-IPI working group. An international prognostic index for patients with chronic lymphocytic leukaemia (CLL-IPI): a meta-analysis of individual patient data. Lancet Oncol 2016; 17: 779-90; https://doi.org/10.1016/S1470-2045(16)30029-8

13. Delgado J, Doubek M, Baumann T, et al. Chronic lymphocytic leukemia: A prognostic model comprising only two biomarkers (IGHV mutational status and FISH cytogenetics) separates patients with different outcome and simplifies the CLL-IPI. Am J Hematol 2017; 92: 375-80; https://doi.org/10.1002/ajh.24660

14. Thompson PA, Tam CS, O'Brien SM, et al. Fludarabine, cyclophosphamide, and rituximab treatment achieves long-term disease-free survival in IGHV-mutated chronic lymphocytic leukemia. Blood 2016; 127: 303-9; https://doi.org/10.1182/blood-2015-09-667675

15. Burger J, Barr P, Robak T, et al. Ibrutinib For First-Line Treatment Of Older Patients With Chronic Lymphocytic Leukemia/Small Lymphocytic Lymphoma (Cl1/S11): A 4-Year Experience From The Resonate-2 Study. EHA Learning Center 2018; 214817. Abstract: PF343

16. Burger JA, Tedeschi A, Barr PM, et al.; RESONATE-2 Investigators. Ibrutinib as Initial Therapy for Patients with Chronic Lymphocytic Leukemia. N Engl J Med 2015; 373: 2425 37; https://doi.org/10.1056/NEJMoa1509388

17. Barr PM, Robak T, Owen C, et al. Sustained efficacy and detailed clinical follow-up of first-line ibrutinib treatment in older patients with chronic lymphocytic leukemia: extended phase 3 results from RESONATE-2. Haematologica 2018; 103: 1502-10; https://doi. org/10.3324/haematol.2018.192328 
18. ESMO guidelines committee Chronic lymphocytic leukaemia: eUpdate published online 27 June 2017. Ann Oncol 2017; 28, 149-52; https://doi.org/10.1093/annonc/mdx242

19. Kipps TJ, Stevenson FK, Wu CJ, et al. Chronic lymphocytic leukaemia. Nat Rev Dis Primers 2017; 3: 16096; https://doi.org/10.1038/nrdp.2016.96

20. Wendtner CM, Dreger P, Eichhorst B, et al. Chronische Lymphatische Leukämie (CLL). Onkopedia leitlinien, 2019. Available at https:/www.onkopedia.com/de/onkopedia/guidelines/chronische-lymphatische-leukaemie-cll/@@guideline/html/index.html (last accessed October 2019)

21. Medina A, Ramírez A, Hernández J, et al. Guía nacional de leucemia linfática crónica y linfoma linfocítico. Grupo Español de Leucemia Linfocítica Crónica (GELLC), 2019. Available at https://www.sehh.es/images/stories/recursos/2019/06/03/Guia-Clinica-LLCcon-Aval.pdf (last accessed October 2019)

22. Mora A, Bosch R, Cuellar C, et al. CD200 is a useful marker in the diagnosis of chronic lymphocytic leukemia. Cytometry B Clin Cytom 2019; 96: 143-8; https://doi.org/10.1002/ cyto.b. 21722

23. Parikh SA, Strati P, Tsang M, et al. Should IGHV status and FISH testing be performed in all CLL patients at diagnosis? A systematic review and meta-analysis. Blood 2016; 127 : 1752-60; https://doi.org/10.1182/blood-2015-10-620864

24. Condoluci A, Terzi di Bergamo L, Langerbeins P, et al. International Prognostic Score For Early Stage Chronic Lymphocytic Leukemia (IPS A). Hematological Oncology 2019, 37 : 81-82; https://doi.org/10.1002/hon.51_2629

25. Baliakas P, Jeromin S, Iskas M, et al.; ERIC, the European Research Initiative on CLL. Cytogenetic complexity in chronic lymphocytic leukemia: definitions, associations, and clinical impact. Blood 2019; 133: 1205-16; https://doi.org/10.1182/blood-2018-09-873083

26. Imbruvica - Summary of Product Characteristics

27. Zydelig - Summary of Product Characteristics

28. Venclyxto - Summary of Product Characteristics

29. AIFA - Imbruvica monitoring registry. Available at https://www.aifa.gov.it/it/web/guest/ registri-e-piani-terapeutici1 (last accessed October 2019)

30. Woyach JA, Ruppert AS, Heerema NA, et al. Ibrutinib Regimens versus Chemoimmunotherapy in Older Patients with Untreated CLL. N Engl J Med 2018; 379: 2517-28; https:// doi.org/10.1056/NEJMoa1812836

31. Gozzetti A, Candi V, Fabbri A, et al. Chemoimmunotherapy with oral low-dose fludarabine, cyclophosphamide and rituximab (old-FCR) as treatment for elderly patients with chronic lymphocytic leukaemia. Leuk Res 2014; 38: 891-5; https://doi.org/10.1016/j. leukres.2014.05.016

32. Shanafelt TD, Wang XV, Kay NE, et al. Ibrutinib-Rituximab or Chemoimmunotherapy for Chronic Lymphocytic Leukemia. NEngl J Med 2019; 381: 432-43; https://doi.org/10.1056/ NEJMoa1817073

33. Fischer K, Bahlo J, Fink AM, et al. Long-term remissions after FCR chemoimmunotherapy in previously untreated patients with CLL: updated results of the CLL8 trial. Blood 2016; 127: 208-15; https://doi.org/10.1182/blood-2015-06-651125

34. Eichhorst B, Fink AM, Bahlo J, et al.; international group of investigators; German CLL Study Group (GCLLSG). First-line chemoimmunotherapy with bendamustine and rituximab versus fludarabine, cyclophosphamide, and rituximab in patients with advanced chronic lymphocytic leukaemia (CLL10): an international, open-label, randomised, phase 3, non-inferiority trial. Lancet Oncol 2016; 17: 928-42; https://doi.org/10.1016/S14702045(16)30051-1 